\title{
21
}

\section{The Election Online: Debate, Support, Community}

\section{Scott Wright, Verity Trott and William Lukamto}

This chapter analyses everyday online political talk about the 2016 Australian federal election. Rather than focusing on the usual suspects of candidates' social media interactions and party websites' interactive features (e.g. Macnamara and Kenning 2014), this study addresses a 'new agenda' for online deliberation. This is the study of everyday talk about the election as it emerges in a formally non-political, online 'third space': a discussion forum devoted to parenting (Wright 2012a, 2012b; Wright, Graham and Jackson 2016). In doing this, the chapter addresses a gap in studies of Australian election campaigning, including across the previous volumes of this series, and more generally in the field of online deliberation research.

To this end, the chapter analyses three principal research questions. First: what is the discursive nature of debate about the election? This question analyses the rationality of debate; the extent to which people are engaged in debate versus stand-alone comment; the existence of negative behaviours such as 'flaming', 'curbing' and 'trolling'; and, finally, the extent to which debates are politically polarised with the left talking to the left, and the right talking to right. The second research question is: how do people talk about the election process and voting? This question looks at how people talk about the process of voting and vote choices. This includes whether people talk about the experience of voting (e.g. sausage sizzles); 
their election knowledge; discussions and declarations of who to vote for; specific reasons for their vote choice; and whether they discuss political personalities, ideology or express disillusion/disappointment or praise/ support for the parties. The third research question is: to what extent do people talk about key election themes? This analyses the extent to which the debate focused on themes such as marriage equality, the environment, the economy and so on. To answer the questions, the chapter provides a detailed analysis of nearly 700 comments posted in three threads that focus directly on the election. This is combined with an over-arching analysis of all participants.

\section{The internet and Australian federal elections}

With each federal election, new hope and hype is placed on the apparent power of the internet to change electoral practice. Research has shown that political parties and politicians have been broadly following international trends on electioneering adopting, if not necessarily adapting to, new technology, but often with limited mainstream impact (e.g. Chen 2008; Flew and Wilson 2008; Gibson, Lusoli and Ward 2008; Gibson and McAllister 2008; Gibson and Ward 2008; Macnamara 2008; Macnamara and Kenning 2011, 2014). Rachel Gibson and Marta Cantijoch's (2011) comparison of the 2010 UK and Australian elections suggested communication by politicians was largely in the traditional broadcast form, with limited interaction. Jim Macnamara and Gail Kenning (2014: 13) analysed candidates' social media use during the 2013 federal election, finding that while usage increased overall, their interactive dialogue decreased from the 2010 election in favour of more broadcast communication-leading them to argue that communication remains largely 'politics 1.0'. Axel Bruns's (2016; see also Bruns and Burgess 2011) analysis of Twitter use found that the Labor Party was twice as active as the Coalition, with the Greens candidates the most active. Coalition tweets were largely from the frontbench, which was interpreted as an attempt to control the message.

The Australian 'e-lection' literature follows a similar theoretical and methodological approach to 'e-lection' literature internationally (e.g. Gibson et al. 2003; Lilleker et al. 2011; Stromer-Galley 2003; Vaccari 2008). First, much of the literature is theoretically framed by the polarising normalisation, or equalisation, approach to 
understanding impact. This is unhelpful because it can warp the analysis of results, underplaying incremental change (Wright 2012a). Second, the literature has largely focused on analysing how politicians and parties engage (or not) online, and how people respond and react to them (e.g. Macnamara 2008, Macnamara and Kenning 2014). While this focus on the political elite is undoubtedly interesting and important, it ignores the vast majority of political talk that occurs between, and amongst, citizens. Thus, when scholars talk about the impact of the internet on elections, they are providing a very narrow picture of events. In an apparently web 2.0 social media age, it seems peculiar to continue to focus on these elites at the expense of everyday talk.

One helpful counterpoint here is Tim Highfield's (2016) lucid, insightful and important study of social media and everyday politics. It provides a discursive analysis and account of everyday online civic rituals during the election day, and how these sometimes clash with social media norms. This includes the 'democracy sausage' as part of the voting experience, and rules on taking photos within polling stations. However, the quantitative empirical data focuses on election hashtags such as \#ausvotes. While at face value, Twitter seems to be an everyday political space, the organisational role of election hashtags may limit this because they are politically defined and widely used by the political elite and activists. In addition, Twitter has been disproportionately examined for political talk online at the cost of overlooking spaces less dominated by the political and media elite. This may still, thus, be a relatively narrow account that fails to capture the average citizen (Highfield 2016: 144).

What has largely been missing across the Australian online election literature is an analysis of how online election debates emerge beyond these politically defined spaces, such as those devoted to self-help, lifestyle or popular culture. This chapter addresses this limitation. The gap is important because the space of political talk matters. Space shapes the nature of debate. Whether it is interface design (Wright and Street 2007), moderation (Edwards 2002; Wright 2002, 2006) or the topic and structure of the space (Wright 2012b), the design of forums - like parliamentary debating chambers-matters. Following new institutionalist theory, this design is not just the formal institutional structures, but also includes the informal rules and norms of debate that shape how people interact discursively. To unpack this claim in more detail, we turn to address the nature and importance of everyday political talk in non-political, online 'third spaces'. 


\section{Everyday online political talk in non-political spaces}

Everyday online political talk encompasses a wide variety of political debate. As opposed to formal political talk, it is citizens rather than political elites that create everyday election debate. Such debate can be messy, mundane and draw on humour, and can emerge in the process of everyday conversation. We argue that everyday online political talk matters during elections. It matters because such talk helps to develop a sense of citizenship and civic identity, and is important to the microdynamics of democracy (Dahlgren 2006). But political talk is not just a contextual resource sitting in the background. Rather, more specifically, to the extent that people talk about the election, it is in this general public sphere where (typically mediated) campaign messages and debates are refracted, distilled and through which a sense of personal and public opinion can form. Thus, while people may primarily consume election material through the mediated public sphere, it is deconstructed, interpreted and reconstructed through the everyday public sphere and political talk. If it is correct that the mediated public sphere-often linked to a broader 'dumbing down' of politics amid attempts to package politics (Franklin 1994) - is denuding citizens of their civic capacity and social capital (Putnam 2000), can everyday political talk help to mitigate some of these concerns? Does talking about politics online, particularly in a public, community context, lead people to become more politically active (Graham, Jackson and Wright 2015, 2016; Wright 2015)? While the brief account of civic talk outlined above would suggest some hope, there are also many concerns about the contemporary state of (on and offline) political talk itself.

First, online political talk often becomes polarised, with people able to ignore those with whom they disagree, narrowcasting to a group of likeminded people as a kind of 'Daily Me' (Sunstein 2001) that reinforces rather than challenges views (Van Alstyne and Brynjolfsson 1997: 3-4; Smith et al. 2014). Second, people may simply choose to avoid political talk (Eliasoph 1998), or avoid talking about politics if they perceive that others hold differing views, or they are in a minority (Mutz 2006; Mutz and Martin 2001)_again, avoiding disagreement. Where this 'norm' is breached, people may 'unfriend' the people that do not adhere (John and Dvir-Gvirsman 2015). Third, political talk online can descend into aggressive 'flame wars' and 'trolling', with debates going off topic 
(e.g. Davis 1999, 2005; Wilhelm 2000). Finally, online political debates are often found to have highly active minorities that dominate activity (Davis 2005; Wright 2006, 2007). This is problematic for some theories of deliberation, which typically argue that deliberation either requires broadly equal participation, or at least the opportunity to deliberate equally (Dahlberg 2001). There are, thus, many potential challenges for online deliberation. We contend, however, that political talk that emerges in certain kinds of non-political, online spaces-what we call third spaces-may have the potential to overcome these challenges.

At its most basic, a third space is an online public space that exists beyond home (first space) or work (second space), where people can come together for informal conversation and socialising. The concept of third space is built on a critique of Ray Oldenburg's concept of third place. Oldenburg's third places are place-spaced venues (such as pubs and cafés), where people can meet and interact informally, and where political talk emerges. Oldenburg argues they perform a crucial role in the development of societies and communities, helping to strengthen citizenship and thus are 'central to the political processes of a democracy' (1999: 67). However, Oldenburg argues the third place is in serious decline-in part, because of the internet. Indeed, Oldenburg is highly critical of the idea of virtual community, on which the concept of third space is based (see Wright 2012b for a detailed account). We argue that online communities can indeed be communities (following Rheingold 1993; Schuler 1996; Bruckman and Resnick 1995; Wellman 1998) and they are important to democracy. While we cannot get into all of this debate here, it is important to address how they might provide an important venue for political talk (see Wright 2012a, 2012b).

We hypothesise that political talk in third spaces will feature important characteristics of deliberation. First, we hypothesise that comments will be discursive, with people engaged in sustained debates. Second, we hypothesise that comments will generally be rational, defined as people using evidence to support claims as opposed to making unsupported assertions. Third, we hypothesise that there will be limited 'flaming', 'trolling' and 'curbing'. Such negative behaviours are a significant issue in online debate. We argue that this will be limited for a variety of reasons, including that there are strong community norms and moderation that maintain a broadly respectful tone; many participants are regulars and know each other; and the space is not politically defined, which means that people from a wide variety of political persuasions are likely to 
participate. Fourth, building on both Oldenburg's positive analysis of the role of 'regulars' in third places, and the more positive analyses of the impact of frequent posters in online political debate, it is hypothesised that there will be 'regulars', or 'super participants', and they will have a positive impact on debate. Finally, while we cannot address this in detail here, we hypothesise that political polarisation will be limited in a third space. This is because the forum is not politically defined and should, thus, feature participants with a wide range of political views. Moreover, political talk can, in theory, emerge in a wide range of subforums-beyond the political and news sections of the forum-making it harder for people to avoid politics (Brundidge 2010: 695; Eliasoph 1998). In combination, this makes crosscutting (left-right) political talk more likely to occur (see Wright, Graham and Jackson 2016 for an empirical study).

\section{Methodology}

The method adopted for this study was a manual content analysis. Data was collected from the forum using a web-scraping tool—Outwit Hub Pro-and stored offline in a database. To identify threads that talked about the election, we used a single keyword search, 'election'. We chose to select only threads that focused specifically on the election because the study is part of a broader comparative project and we found that search functions return different kinds of data, impeding comparability. This sampling method controlled for this limitation. However, this is also likely to undermine some of the key normative benefits of third spaces: political talk within a political subforum is likely to be different to a nonpolitically defined subforum. This is because politically defined spaces are likely to attract the already politically interested, while others might choose to ignore or avoid the political sections of the forum. This may, in turn, lead to greater polarisation and flaming. In practice, we discovered that there was limited talk about the election outside of the three threads, and that these were in an election subforum. Moreover, we observed that the moderators were moving other threads into one big election thread to maintain continuity. One single thread accounted for 95 per cent of all the posts across the three election threads. This moderation policy is likely to further impact debate. 


\section{Content analysis}

The principal method for analysing the nature of the debate was content analysis. We divided the content analysis framework into four separate sections, and they were coded in four phases to increase reliability. The coding manuals were tested and refined, and coders were trained to enhance reliability. Intercoder reliability testing was conducted using Freelon's Re-Cal platform. Reliability scores were high across the board, particularly when we consider that the sample was small and many codes were infrequently applied and that one error would heavily impact reliability (Kappa).

Table 21.1. Reliability test results

\begin{tabular}{|l|r|r|}
\hline & Cohen's Kappa & Agreement (percentage) \\
\hline Election codes & 0.72 & 88.9 \\
\hline Topic of debate & $0.85^{\star}$ & 99.3 \\
\hline Nature of debate & $0.87^{\star}$ & 95.6 \\
\hline
\end{tabular}

Note. $\mathrm{n}=71$.

* Includes codes with 100 per cent agreement recorded as 1.0 for perfect reliability

Source. Data collected and coded by authors from an online parenting forum.

\section{Phase 1: Nature of debate}

First, we present our method for analysing the nature of debate. Our initial step was to analyse the discursivity of debate: messages were coded as a stand-alone comment when they did not reply to another message; coded as a seed message if they were at the start of a thread; a reply when messages were a reply to another message; or a reciprocated exchange when there was a comment, reply and a further reply. Second, we analysed whether a message was a rational claim or an assertion. That is, was a claim supported with some kind of reason or evidence, or was it just a claim? For example, 'Labor's negative gearing policy is crazy because it will harm the middle class', would be coded as a rational claim whereas, 'Labor's negative gearing policy is crazy', would be coded as an assertion. Finally, we coded for critical reflection: a rationalised claim that directly challenges or refutes another claim in the thread or beyond. This is indicative of crosscutting political talk. The final step was to analyse for negative behaviours. We coded for degrading comments that attempted to lower the character, quality, esteem or rank of another participant or 
the participant's claims (e.g. 'you're an idiot', 'you don't know what you're talking about', 'It is stupid to argue that climate change is real'). Curbing messages were attempts to suppress or restrict another participant's claim, argument, position, opinion or statements in general. This includes statements like 'you don't belong in this forum', 'shut up' and 'you need to stop posting'. Finally, flaming was coded in messages where people used foul language or were aggressive. We also coded for one further positive behaviour, when users acknowledged other users with words of encouragement, compliments, thanking and statements of sympathy such as 'you're amazing', 'great work' and 'thanks for your support'.

Alongside these codes, we also recorded whether a poster was a 'super poster' (more than 2,000 posts); the total number of posts made in the three threads by each participant; and whether the post was made by a moderator or community staff (which was clearly identified) to add granularity to the analysis and to allow us to assess the impact of super participants and the regulars (Graham and Wright 2014).

\section{Phase 2: Election codes}

The second phase of the coding analysed how people talked about their election experience and voting in various ways. First, we coded for whether people talked about the voting experience. This was informed by Stephen Coleman's (2013) important study of how people perceived the road to voting. Here, coders were looking for mentions of the experience of voting, such as talk about the sausage sizzle, wait times, whether people stated that they liked/hated voting and also discussions of the media coverage of voting (as a mediated voting experience). Second, we coded for whether people stated that they had limited political or election knowledge. This code included statements like 'I don't know who the leader is' and 'I don't understand their policy'. Third, we coded for vote choice talk in which people talked about who to vote for, including statements of intention as well as debates about who to vote for. Fourth, we analysed whether people gave a reason for who they were voting for, such as 'I am voting Liberal because my parents did' or 'because I believe in low taxes'. Fifth, we coded for whether people expressed uncertainty about who to vote for. Sixth, we coded for whether people sought or provided election help on the process of voting, specifically focusing on technical matters such as how to vote, when polling stations were open and when was the best time to vote (discussions of who to vote for were coded as vote choice 
talk). Seventh, we coded for whether people commented on party policies such as negative gearing, health and the environment. Eighth, we coded for whether people commented on political personalities including the party leaders, MPs and general comment on whether politicians were good or bad. Ninth, we coded for specific reference to political ideology (this included statements about parties lacking ideology). Tenth, we coded for expressions of disillusion or disappointment with politics and politicians, including complaints about parties, leaders or the election process. Eleventh, we coded for expressions of support, praise or happiness with Australian parties, politicians or policies. Finally, we coded for whether the posts contained personal information about the poster or their family such as discussions about their personal situation and experience.

\section{Phase 3: Topic of comments}

Our third phase focused on what we had identified as key topics in the election, to see the extent to which they have been picked up and commented on within the forum. This is not an exhaustive list, though having read all of the comments, we believe it does cover a significant amount of all of the political talk. This was not a dominant code (in other words, if people talked about the environment and infrastructure in the same comment it would be coded twice):

- Environment: climate change, agriculture, animals, environment in general

- Asylum and immigration: 'turn backs', offshore detention, rights of immigrants, integration of immigrants

- Indigenous affairs: land rights, Indigenous education, health, equality, racism towards Indigenous Australians

- Science and technology: research, science, space, tech industry

- Education: schools, universities, childcare/preschool

- Economy: budget, deficit, growth, health of economy, who people trust to run economy, unemployment, jobs

- Housing and real estate: rental prices, negative gearing, house costs, house building, apartment block development

- Infrastructure: roads, public transport, airports, National Broadband Network and internet cabling

- Health and welfare: Medicare, Centrelink, benefits, hospitals, doctors. 


\section{Phase 4: Political views}

This set of codes analysed whether each individual participant in the thread expressed either a direct political affiliation (e.g. 'I support the Greens') or a general political affiliation (e.g. 'I vote for left-leaning parties'). We used this to analyse the spread of political affiliations of users; the total numbers of comments of people from the left and right (by marking every comment from someone who said they voted Labor or left with their view); and whether people engaged in crosscutting political talk between left and right. Occasionally, people made who they voted for explicit without specifying a party or stating a left/right affiliation (e.g. 'I believe in higher taxation and a strong welfare state and more funding for schools', would be coded as left leaning; statements such as 'I believe in marriage equality' were not coded as this can apply to left or right). As this proved reliable, we included these as well as explicit left or right statements. Where people stated which party they supported or voted for, this was coded as their political view throughout. If people stated they voted in a certain direction, we checked their other posts to see if there were specific statements of support for a party. Similarly, where no political affiliation was given in the first comment of a poster, we checked their other comments to see if a political affiliation was given. Where people contradicted themselves (very rare), this would be coded as unclear. Our categories were: Left, Labor Party, Liberal, National, Green, Independent Right, Independent Left, Independent unspecified (states 'supports Independents' with no other clarifying information), Right (including statements such as I support the Coalition), undecided (e.g. I am still thinking, I am not sure) and unclear (where no view was given, or it was unclear/contradictory).

\section{Findings}

\section{Nature of debate}

The debates were highly interactive and discursive, with no evidence of people talking past each other, or just commenting without engagingsupporting hypothesis one. Within the election threads, we found that 18 per cent of posts were (single) replies (most of these occurred near the start as a series of people replied to an initial question, before it turned into a debate), with 81 per cent of posts being interactive, 'reciprocated 
exchanges' and only 1 per cent of the posts were coded as 'standalone comments' - typically a question starting a new debate. The default form of communication was a reciprocal debate with people often engaged in sustained interaction over a number of posts. However, interaction does not necessarily equal deliberation. Indeed, we might expect there to be more negative discursive behaviour in a highly interactive environment. Thus, we move to the content of the debates.

Figure 21.1 indicates that the quality of debate is generally high, with 47 per cent of comments coded as 'rational', using evidence to support claims, compared to only 15 per cent of comments coded as 'assertions'. In addition, a further 15 per cent were 'critical reflections', showing that a minority of debates featured users providing counter claims that were specifically in response to another user's argument. Furthermore, there was very limited evidence of negative discursive behaviours such as degrading, flaming and curbing, and people often acknowledged each other, indicative of a community structure.

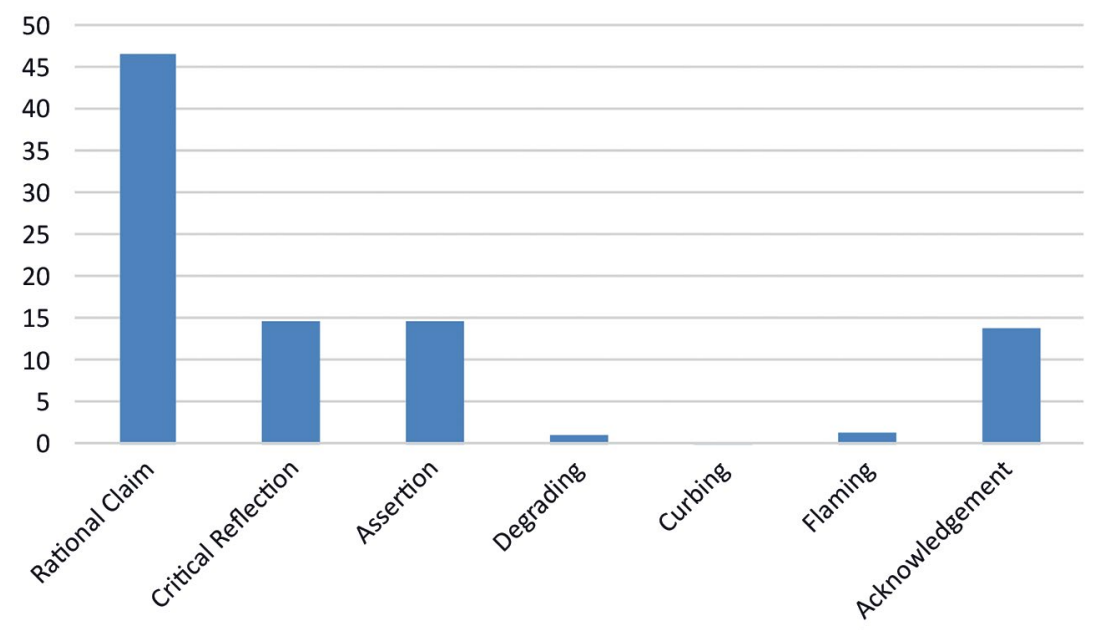

Figure 21.1. The nature of debate

Source. Constructed by authors from data collected from an online parenting forum.

A closer analysis of the content of the debates suggests users find ways to relate to other users who hold differing political alignments and attempt to find common ground with each other. Users illustrated a constructive and considerate type of engagement where they reflected and expanded upon another user's claim rather than blatantly disagreeing with it. This is reflected in a specific debate in which some left-aligned users talk 
with two liberal voters about their similar views on social issues, such as marriage equality and asylum-seeker rights. A few users expressed surprise at their shared views and further attempted to understand where their differences emerged. When we consider the topics of debates were often difficult, sensitive issues - for example, around asylum seekers — and that the exchanges were highly interactive, the results strongly suggest these debates had a deliberative character and were surprisingly high in quality, supporting hypotheses two and three.

This display of genuine and civil deliberative political discourse emphasises the value of the forum as a third space. It highlights how everyday political talk online helps individuals to construct their own civic identity while also enabling them to contextualise their own views amongst others in their community. The practice of finding common ground with each other also helps develop a sense of empathy and mindfulness with differing views, further strengthening the bonds between members of the community and provoking some of the users to consider alternative perspectives.

\section{Political affiliation}

We identified 71 users participating within the three election threads of the forum. A user is considered a participant if she or he posts at least once. For each of these users, we further determined which parties or ideology they identified with. Table 21.2 shows that 28 participants had a leftwing affiliation within the election threads (self-identifying as left, Labor or Green). This contrasts with only 13 users identifying as conservative voters - with no Nationals visibly participating. Furthermore, 29 users were either unclear or undecided about their political alignment. This indicates that this third space has at least the potential for crosscutting political talk through which voters' views and choices have the potential to be shaped through debate. There was, however, an imbalance in participation with people from the left commenting more frequently, and one Liberal poster being the most frequent commenter overall within the threads. The comment structure within the threads was also unequal: the top 10 posters within the three threads had made 65 per cent of the comments. However, given the broadly positive findings of this research, it suggests that the regulars have a positive impact on debate (hypothesis 4). Initial analysis of polarisation indicates that the debates were not polarised, with people engaging in crosscutting political talk with significant disagreement (Wright, Lukamto and Trott 2016). 
Table 21.2. Political affiliation

\begin{tabular}{|l|r|r|r|r|}
\hline Political Identification & $\begin{array}{c}\text { No. of } \\
\text { posts }\end{array}$ & $\begin{array}{c}\text { No. of } \\
\text { users }\end{array}$ & $\begin{array}{l}\text { No. of super } \\
\text { posters }\end{array}$ & $\begin{array}{l}\text { No. of comments } \\
\text { by super posters }\end{array}$ \\
\hline Left & 194 & 20 & 8 & 62 \\
\hline Right & 11 & 3 & 2 & 8 \\
\hline Labour & 83 & 3 & 3 & 79 \\
\hline Liberal & 131 & 5 & 2 & 14 \\
\hline National & 0 & 0 & 0 & 0 \\
\hline Green & 88 & 5 & 3 & 55 \\
\hline Independent unspecified & 6 & 4 & 0 & 0 \\
\hline Undecided & 13 & 3 & 1 & 11 \\
\hline Unclear & 66 & 26 & 14 & 30 \\
\hline Total & 594 & 71 & 33 & 259 \\
\hline
\end{tabular}

Source. Data collected and coded by authors from an online parenting forum.

We also analysed the 'super posters' (users who had posted more than 2,000 comments on the forum) or 'regulars', and discovered that while there were only three super posters who were self-declared Labor voters, they were extremely active within the thread. These three Labor supporters combined were responsible for 79 of the comments within the election thread, highlighting the dominant role their voice played within the election debates. Right-leaning and Liberal-associated 'super posters' were infrequent posters, by comparison, with only 22 comments combined. Super posters in total contributed 31 per cent of the total number of posts, which is slightly less than the overall average for the forum. If we consider both the analysis of super posters and the most frequent participants in the thread, alongside the broadly positive findings presented here, it suggests that a group of regulars is important to setting the tone of debate (hypothesis 4).

\section{Election topics}

As is shown in Figure 21.2, there were three key election topic themes that were prominent in the election threads. First, there was a large amount of discussion around asylum seekers and immigration (22 per cent of all posts), much of which was about revulsion for Pauline Hanson and the far right. Second, discussions about the economy were prominent (11 per cent of all posts), with users comparing the two major parties' differing approaches to economic policy. Third, discussion around marriage equality 
was quite common ( 9 per cent of all posts). There was ubiquitous support for marriage equality with lots of frustration over the proposed plebiscite and Malcolm Turnbull; many users voiced their desire for the bill to be passed and to stop wasting time and taxpayers' money. It was noticeable that the environment and real estate (for example, negative gearing) were barely mentioned ( 2 per cent and 0.3 per cent of all posts, respectively). The former is quite surprising as there were several Green supporters in the thread, but they largely debated on social issues. There was also a notable lack of discussion surrounding Indigenous affairs (only one post mentioned Indigenous issues and that was in relation to the first Indigenous woman to be elected into the House of Representatives). ${ }^{1}$ The dominant role played by the three topics reflects that discursive structure of the debate: these topics were talked about at length and with multiple participants.

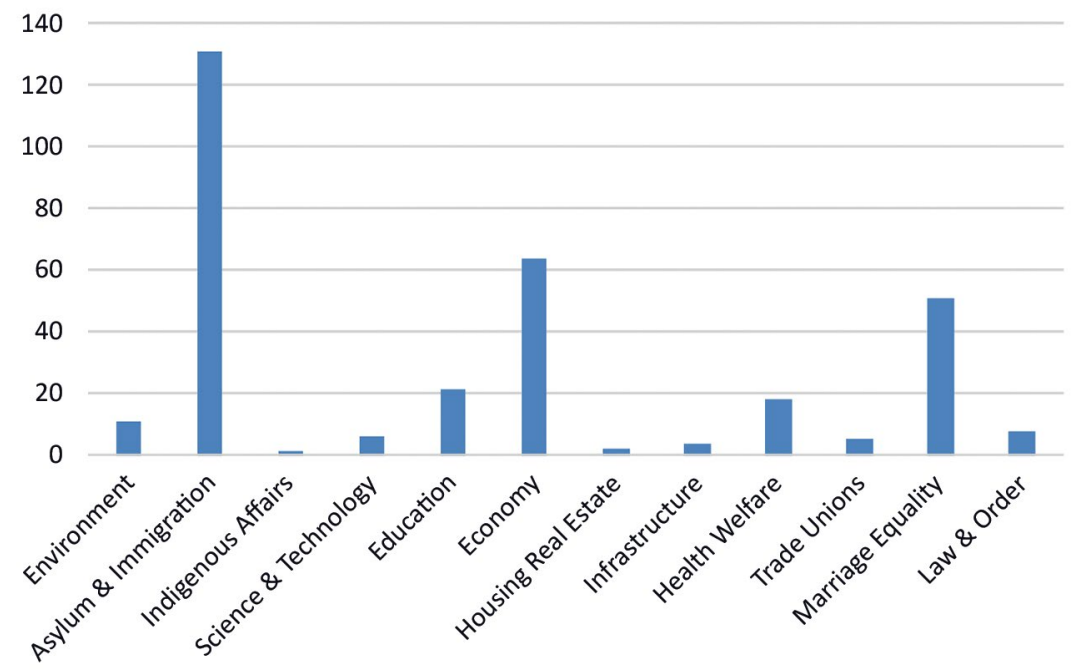

Figure 21.2. Election topics

Source. Data collected and coded by authors from an online parenting forum.

Using content analysis, we cannot determine whether the broader user base was avoiding political talk. However, the results show that the people who participated avoided neither difficult topics nor disagreed with each other (Wright, Lukamto and Trott 2016). That the debate was of a relatively high quality (in terms of rationality, discursive structure, crosscutting) is all the more surprising given the topics of debate.

1 For an analysis of the discussion on Indigenous issues in the election, see Perche, Chapter 27, this volume. 


\section{Election experience}

Within our election vote codes, we discovered that there was a substantial amount of talk about political personalities (Figure 21.3), which was often accompanied by feelings of disappointment. Some of this can be attributed to the original poster raising a secondary question: who is the worst politician of all time? Users often compared Tony Abbott and Turnbull, and expressed dismay toward Hanson. However, a few users shared positive sentiments with declarations of support and praise for Penny Wong, and one person expressed support for Hanson. Within these discussions, it became clear there was a commonly shared sense of dissatisfaction with the two major parties.

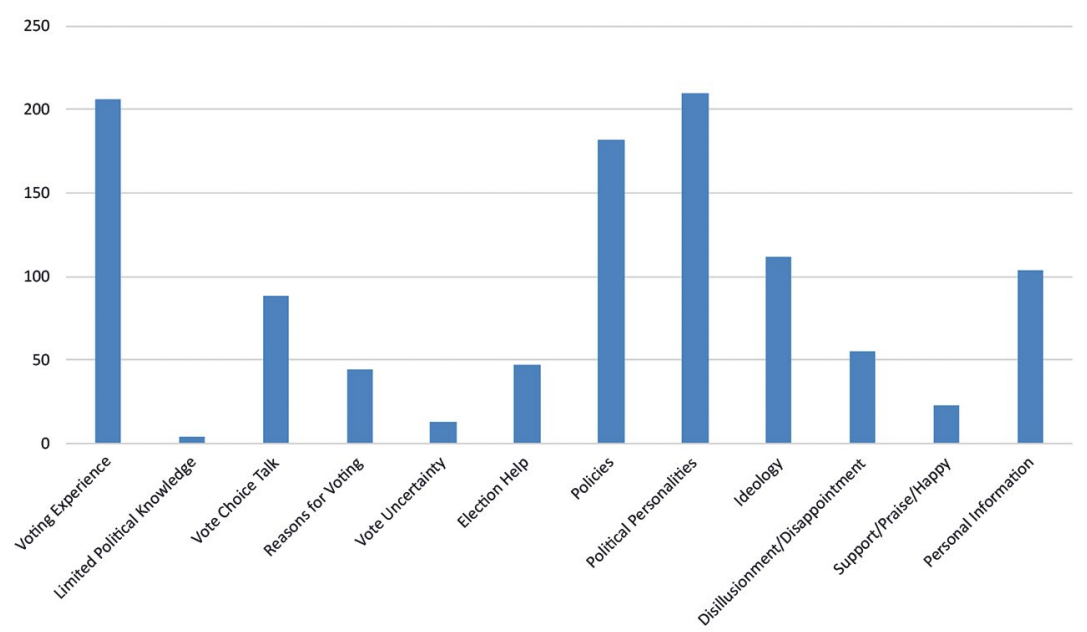

Figure 21.3. Election experience

Source. Data collected and coded by authors from an online parenting forum.

Our codes revealed that there was a lot of talk about the voting experience-this was predominately about the experience of voting at the polling booth, including queues and 'democracy sausages' (or sausage sizzles). People were keen to talk about the social experience of voting, including their personal experience. This can be understood as another part of the civic ritual literature to the extent that people were looking to make the experience more enjoyable, and it supports literature that focuses on how people experience the road to voting, and how authorities might enhance this (Coleman 2013; Highfield 2016). This also included people's experiences watching the $\mathrm{ABC}$ coverage of the election results as votes were being counted. The conversations that surrounded the $\mathrm{ABC}$ coverage 
were particularly interesting as they depicted a shared collective experience of users simultaneously watching and discussing what was occurring on the $\mathrm{ABC}$. As more users engaged in this somewhat live commentary of the $\mathrm{ABC}$, there developed a collective expectation that other users should be watching as well. Users supported each other to stay up and watch or felt compelled to justify why they went to bed and missed it. These types of conversations highlight the ways in which everyday political talk online can motivate citizens to become more politically active as they are compelled to 'stay in the loop' and are encouraged by others to engage further so they understand the political processes occurring.

It was also reasonably common for users to provide help about the election, including explaining the ballot papers and voting process, as well as explaining the vote-counting process and the procedure surrounding the formation of government. A few users made a point of reiterating the new voting process on the ballot for the Senate to ensure everyone was aware of the changes and would be prepared for voting on the day. In addition to the earnestness towards providing help, our findings showed that users appeared to be quite comfortable talking about who they were voting for.

\section{Shaping deliberative spaces}

The results above depict the parenting forum as a particularly respectful third space for political deliberation with low levels of trolling and high levels of reciprocated discussions. To further understand these results, we analyse the social norms and practices that emerged and shed light on how the forum has managed to capture and maintain such genuine debate, and how we might be able to develop other sites into such third spaces.

While arguments rarely devolved into 'flame wars' or personal attacks, when they did happen, other users were found to quickly take up mediatory roles in resolving disputes so that the quarrelling parties were soon placated. This was done by referring to already established common ground between the two parties, or by clarifying any misunderstandings one party might hold. Through this mediation process, disputing parties were found to either 'agree to disagree' or apologise for any hurtful remarks and misunderstandings. This seems to be a social norm that most usersnot just the 'super posters'-adopt. Out of the three disputes found in 
the sample, two were successfully mediated by users who were not super posters. In deliberative terms, consensus won out over conflict between clearly disagreeing parties.

While the reasons for how such a consensual deliberative environment was cultivated were not the focus of this study, we suggest that three factors contributed. First, as a parenting forum, users entered the debates recognising that they already share some common characteristics with other users. This common ground became a foundation for friendships and trust to be built between different users who might not support the same political party, policy or ideology. Second, the forum is built around the desire to develop a supportive space for parents where they can build a trusted community to share information, resources and experiences that loosely revolve around pregnancy and parenting concerns. Users thus enter the forums ready to give and receive support. Third, it seems likely that gender plays a significant role. While it is not possible to determine with accuracy the gender of participants as most users adopt a pseudonym, it seems likely that participants are predominantly women. Tali Mendelberg and Christopher Karpowitz's (2016: 3) overview of research provides a useful account of why this matters:

$[\mathrm{W}]$ omen tend to prefer making decisions through consensus and cooperation, and dislike overt conflict or competition. If women are socialized to cooperate and to seek consensus, while men are socialized to exercise agency and to win conflicts, then by implication women may be motivated to participate in decision-making situations when those situations highlight consensus seeking and avoid overt conflict.

As noted, there was a significant amount of disagreement in the forum, but this rarely became outright conflict and was successfully moderated by other users.

The key tenets of trust and support underpin much of the discourse that is present in the forum. Users were found to often freely share very personal information about themselves and their experiences associated with conceiving and parenting. The standard practice of sharing personal information is carried over into the election threads where we can see that over 100 comments contain personal information. While these bonds and norms have the potential to suppress disagreement and create political polarisation, our analysis indicates that this was not happening (see also Wright, Lukamto and Trott 2016). 


\section{Conclusion}

Overall, the political talk on the forum has deliberative characteristics, with limited evidence of negative discursive behaviours. This appeared, in part, to be because of a supportive environment with a shared interest, and many people knew each other and had trust. It also seems likely that gender plays an important role, though more research is necessary using (or combining) different methods to address this topic. The moderators did not play a significant role within the thread, though they did move other threads to this section to centralise the talk. Although participants were predominantly from the left, Scott Wright, William Lukamto and Verity Trott (2016) identify significant crosscutting political talk that often involved disagreement. Left-leaning people acknowledged participants with right-leaning views with phrases like 'we still love you' or 'we shall agree to disagree'. This created a relatively supportive platform for more right-wing users to voice their opinions: it was disagreement with limited conflict let alone flaming. The topic of debate was dominated by sensitive political issues such as asylum and marriage equality, which makes the tone of the debate all the more surprising. Many people seemed happy to talk about their political views and to support people with the more technical side of voting. Finally, people talked quite extensively about the experience of voting and particularly the sausage sizzle.

\section{References}

Bruckman, Amy and Mitchel Resnick. 1995. 'The MediaMOO Project: Constructionism and professional community'. Convergence 1(1): 94-109. doi.org/10.1177/135485659500100110

Brundidge, Jennifer. 2010. "Encountering "difference" in the contemporary public sphere: The contribution of the internet to the heterogeneity of political discussion networks'. Journal of Communication 60(4): 680-700. doi.org/10.1111/j.1460-2466.2010.01509.x

Bruns, Axel. 2016. '\#ausvotes revisited: Social media in the 2013 Australian federal election'. The Conversation, 9 May. Available at: theconversation.com/ausvotes-revisited-social-media-in-the-2013australian-federal-election-59086 
Bruns, Axel and Jean E. Burgess. 2011. '\#ausvotes: How Twitter covered the 2010 Australian federal election'. Communication, Politics \& Culture 44(2): 37-56.

Chen, Peter. 2008. 'Australian political parties' use of Youtube 2007'. Southern Review: Communication, Politics and Culture 41(1): 114-41.

Coleman, Stephen. 2013. How Voters Feel. Cambridge: Cambridge University Press.

Coleman, Stephen and Jay G. Blumler. 2009. The Internet and Democratic Citizenship: Theory, Practice and Policy. Cambridge: Cambridge University Press. doi.org/10.1017/CBO9780511818271

Dahlberg, Lincoln. 2001. 'Computer-mediated communication and the public sphere: A critical analysis'. Journal of Computer-Mediated Communication 7(1). doi.org/10.1111/j.1083-6101.2001.tb00137.x

Dahlgren, Peter. 2006. 'Doing citizenship: the cultural origins of civic agency in the public sphere'. European Journal of Cultural Studies 9(3): 267-86. doi.org/10.1177/1367549406066073

Davis, Richard. 1999. The Web of Politics: The Internet's Impact on the American Political System. Oxford: Oxford University Press.

—_. 2005. Politics Online: Blogs, Chatrooms, and Discussion Groups in American Democracy. London: Routledge.

Edwards, Arthur. 2002. 'The moderator as an emerging democratic intermediary: The role of the moderator in internet discussions about public issues'. Information Polity 7(1): 3-20.

Eliasoph, Nina. 1998. Avoiding Politics. Cambridge: Cambridge University Press. doi.org/10.1017/CBO9780511583391

Flew, Terry and Jason Wilson. 2008. 'Citizen journalism and political participation: The Youdecide 2007 project and the 2007 Australian federal election'. Australian Journal of Communication 35(2): 17-37.

Franklin, Bob. 1994. Packaging Politics: Political Communications in Britain's Media Democracy. London: Edward Arnold. 
Gibson, Rachel K. and Marta Cantijoch. 2011. 'Comparing online elections in Australia and the UK: Did 2010 finally produce "the" internet election?' Communication, Politics \& Culture 44(2): 4-17.

Gibson, Rachel, Wainer Lusoli and Stephen Ward. 2008. 'The Australian public and politics on-line: Reinforcing or reinventing representation?' Australian Journal of Political Science 43(1): 111-31. doi.org/10.1080/10361140701842607

Gibson, Rachel. K., Michael Margolis, David Resnick and Stephen J. Ward. 2003. 'Election campaigning on the WWW in the US and the UK: A comparative analysis'. Party Politics 9(1): 47-75. doi.org/ $10.1177 / 135406880391004$

Gibson, Rachel and Ian McAllister. 2008. 'Online campaigning in the 2007 Australian election: Did the web deliver votes?' Paper presented at the American Political Science Association Annual Conference.

Gibson, Rachel and Stephen Ward. 2008. 'Introduction: e-politics - the Australian experience'. Australian Journal of Political Science 43(1): 1-11. doi.org/10.1080/10361140701842524

Graham, Todd and Scott Wright. 2014. 'Discursive equality and everyday political talk: The impact of super-participants'. Journal of ComputerMediated Communication 19(3): 625-42. doi.org/10.1111/jcc4.12016

Graham, Todd, Daniel Jackson and Scott Wright. 2015. 'From everyday conversation to political action: Talking austerity in online "third spaces"'. European Journal of Communication 30(6): 648-65. doi.org/ $10.1177 / 0267323115595529$

—. 2016. "We need to get together and make ourselves heard": Everyday online spaces as incubators of political action'. Information, Communication and Society 19(10): 1373-89. doi.org/10.1080/1369 118X.2015.1094113

Highfield, Tim. 2016. Social Media and Everyday Politics. Cambridge; Malden, MA: Polity Press.

John, Nicholas A. and Shira Dvir-Gvirsman. 2015. 'II don't like you any more": Facebook unfriending by Israelis during the Israel-Gaza conflict of 2014'. Journal of Communication 65(6): 953-74. doi.org/ $10.1111 /$ jcom. 12188 
Lilleker, Darren, Karolina Koc-Michalska, Eva Johanna Schweitzer, Michal Jacunski, Nigel Jackson and Thierry Vedel. 2011. 'Informing, engaging, mobilizing or interacting: Searching for a European model of web campaigning'. European Journal of Communication 26(3): 195-213. doi.org/10.1177/0267323111416182

Macnamara, Jim. 2008. 'Internet media and the public sphere: The 2007 Australian e-electioneering experience'. Media International Australia incorporating Culture \& Policy 129(1): 7-19. doi.org/10.1177/132 9878X0812900103

Macnamara, Jim and Gail Kenning. 2011. 'E-electioneering 2010: Trends in social media use in Australian political communication'. Media International Australia 139(1): 7-22. doi.org/10.1177/132 9878X1113900104

—_. 2014. 'E-electioneering 2007-2013: Trends in online political campaigns over three elections'. Media International Australia 152(1): 57-74. doi.org/10.1177/1329878X1415200107

Mendelberg, Tali and Christopher Karpowitz. 2016. 'Power, gender, and group discussion'. Political Psychology S1: 23-61. doi.org/10.1111/ pops. 12320

Mutz, Diana C. 2006. Hearing the Other Side. New York: Cambridge University Press. doi.org/10.1017/CBO9780511617201

Mutz, Diana C. and Paul S. Martin. 2001. 'Facilitating communication across lines of political difference: The role of mass media'. American Political Science Review 95(1): 97-114.

Oldenburg, Ray. 1999. The Great Good Place. Marlow: New York.

Putnam, Robert. 2000. Bowling Alone. New York: Simon \& Schuster. doi.org/10.1145/358916.361990

Rheingold, Howard. 1993. The Virtual Community: Homesteading on the Electronic Frontier. Reading, MA: Addison-Wesley.

Schuler, Douglas. 1996. New Community Networks. New York: ACM Press. 
Smith, Marc A., Lee Rainie, Ben Shneiderman and Itai Himelboim. 2014. 'Mapping twitter topic networks: From polarized crowds to community clusters'. Pew Research Internet Project. Available at: www. pewinternet.org/2014/02/20/mapping-twitter-topic-networks-frompolarized-crowds-to-community-clusters/

Stromer-Galley, Jennifer. 2003. 'Diversity of political conversation on the internet: Users' perspectives'. Journal of Computer-mediated Communication 8(3). doi.org/10.1111/j.1083-6101.2003.tb00215.x

Sunstein, Cass. 2001. Republic.com. Princeton, NJ: Princeton University Press.

Vaccari, Cristian. 2008. 'From the air to the ground: The internet in the 2004 US presidential campaign'. New Media \& Society 10(4): 647-65.

Van Alstyne, Marshall and Erik Brynjolfsson. 1997. Electronic Communities: Global Village or Cyberbalkans? Available at: web.mit. edu/marshall/www/papers/CyberBalkans.pdf

Wellman, Barry. 1998. 'The privatization of community: From public groups to unbounded networks'. In Janet Abu-Lughod (ed), Millennial Milestone: A 'Switching Crisis' in Sociology. Barcelona: International Sociological Association, pp. 89-104.

Wilhelm, Anthony G. 2000. Democracy in the Digital Age: Challenges to Political Life in Cyberspace. London: Routledge.

Wright, Scott. 2002. 'Dogma or dialogue? The politics of the Downing Street website'. Politics 22(3): 135-42. doi.org/10.1111/1467-9256. 00168

- 2006. 'Government-run online discussion fora: Moderation, censorship and the shadow of control'. British Journal of Politics and International Relations 8(4): 550-68. doi.org/10.1111/j.1467856x.2006.00247.x

- 2007. 'A virtual European public sphere? The futurum discussion forum'. Journal of European Public Policy 14(8): 1167-85. doi.org/ $10.1080 / 13501760701656403$

- 2012a. 'Politics as usual? Revolution, normalization and a new agenda for online deliberation'. New Media \& Society 14(2): 244-61. doi.org/10.1177/1461444811410679 
2012b. "From "third place" to "third space": Everyday political talk in non-political online spaces'. Javnost: The Public 19(3): 5-20. doi.org/10.1080/13183222.2012.11009088

__. 2015. "Success" and online political participation: The case of Downing Street e-petitions'. Information, Communication and Society 19(6): 843-57. doi.org/10.1080/1369118X.2015.1080285

Wright, Scott and John Street. 2007. 'Democracy, deliberation and design: The case of online discussion forums'. New Media \& Society 9(5): 849-69. doi.org/10.1177/1461444807081230

Wright, Scott, Todd Graham and Daniel Jackson. 2016. 'Third space, social media and everyday political talk'. In Axel Bruns, Gunn Enli, Eli Skogerbø, Christian Christensen and Anders Olof Larsson (eds), The Routledge Companion to Social Media and Politics. London: Routledge, pp. 74-88.

Wright, Scott, William Lukamto and Verity Trott. 2016. 'Everyday online political talk and the 2016 Australian federal election'. Paper presented at the American Political Science Association Annual Conference. 
This text is taken from Double Disillusion: The 2016 Australian Federal Election, edited by Anika Gauja, Peter Chen, Jennifer Curtin and Juliet Pietsch, published 2018 by ANU Press, The Australian

National University, Canberra, Australia.

doi.org/10.22459/DD.04.2018.21 